\title{
POINT CLOUD-BASED SURVEY FOR CULTURAL HERITAGE. AN EXPERIENCE OF INTEGRATED USE OF RANGE-BASED AND IMAGE-BASED TECHNOLOGY FOR THE SAN FRANCESCO CONVENT IN MONTERUBBIANO
}

\author{
Alessandra Meschini ${ }^{\text {a }}$, Enrica Petrucci ${ }^{\text {a }}$, Daniele Rossi ${ }^{\text {a }}$, Filippo Sicuranza ${ }^{\text {a }}$ \\ ${ }^{a}$ UNICAM, School of Architecture and Design, Viale della Rimembranza, Ascoli Piceno, Italy, \\ alessandra.meschini@unicam.it
}

Commission V

KEY WORDS: SFM, TOF laser scanning, UAV, 3D data integration,

\begin{abstract}
:
The paper aims at presenting some results of a point cloud-based survey carried out through integrated methodologies based on active and passive 3D acquisition techniques for processing 3D models. This experiment is part of a research project still in progress conducted by an interdisciplinary team from the School of Architecture and Design of Ascoli Piceno and funded by the University of Camerino. We describe an experimentation conducted on the convent of San Francesco located in Monterubbiano town center (Marche, Italy). The whole complex has undergone a number of substantial changes since the year of its foundation in 1247. The survey was based on an approach blending range-based 3D data acquired by a TOF laser scanner and image-based 3D acquired using an UAV equipped with digital camera in order to survey some external parts difficult to reach with TLS. The integration of two acquisition methods aimed to define a workflow suitable to process dense 3D models from which to generate high poly and low poly 3D models useful to describe complex architectures for different purposes such as photorealistic representations, historical documentation, risk assessment analyses based on Finite Element Methods (FEM).
\end{abstract}

\section{INTRODUCTION}

This experiment is part of a research project that is still in progress (PRO-CULT: A PRObabilistic performance-based methodology for seismic risk assessment of CULTural heritage). It is being carried out by an interdisciplinary team from the School of Architecture and Design in Ascoli Piceno, and is funded by the University of Camerino. The people involved in this project come from different fields seismology, probability theory, structural dynamics, architectural history, rehabilitation and survey — since risk assessment, which represents the main topic of this research, is typically an interdisciplinary topic.

One of the main objectives of this research was the development of an accurate 3D model that could be used for different purposes, such as the photorealistic representation of the current state in order to historically document the convent of San Francesco in Moterubbiano (Marche, Italy), not only as documentation to conserve and enhance the cultural heritage but also as representations to be further developed, for example, for risk assessment analyses based on Finite Element Methods (FEM) with the aim of investigating the building structure and consequently assessing possible earthquake damage, especially in seismically active areas such as the Marche Region.

With this goal, once we had analysed the volumes of the Convent and in particular the position that it occupies at the downtown of Monterubbiano, separate from other adjacent buildings only by narrow passageways, we decided to integrate two reality-based capture methods in order to achieve dense 3D models from which we could generate high- and low-poly-3D models. A point-cloud-based survey carried out through integrated methodologies is presented in order to develop a hybrid workflow combining the advantages and best performance of each sensor. (Remondino 2011) (Fiorillo et al. 2013)

As for the capture of 3D data pertaining to the architecturalcultural heritage the use of aerial photogrammetry is combined with and often completes surveying sessions based on TLS (Remondino 2011). For this purpose high-resolution digital cameras mounted on unmanned aerial vehicles (UAV) allow impossible points of view to be reached with TLS from adjacent buildings or appropriately placed light scaffolding. While scientific literature in the field of TLS is wide and exhaustive, possibilities regarding the use of UAVs equipped with cameras or even light TOF laser scanners have still not been fully verified (Colomina 2013).

UAVs represent one of the emerging technologies in photogrammetry. This technology is suitable to innumerable applications such as TV and film recording, the maintenance of infrastructures. There are also many uses for surveillance and control vast areas, as well as surveying the topography or individual architectural constructions (Colomina 2013).

\section{CASE STUDY}

\subsection{Historical background}

The case study is the small convent of San Francesco situated on the highest part of Monterubbiano (Province of Fermo, Marche, Italy). The ridge sits above the Aso River, part of the mountainous comb structure that reaches the Adriatic Sea after marking the territory.

Many historic towns can be seen along the river valley. The different settlements, each with its own particularities, present common characteristics: a very compact urban fabric surrounded by walls that have been more or less conserved over 
the centuries, traversed by paths running between the houses and opening in the squares in front of city buildings and monasteries.

Monterubbiano is characterised by a variety of interesting architecture. The Franciscan complex is among the most representative buildings in the old city. The Church of San Francesco with its cloister dates from 1247, between the domination of Fermo and the birth of the cities. The church was modified in 1428 when the wooden trusses of the roof were demolished and substituted with the current brick vaults. At the beginning of the 17 th century, the orientation of the church was inverted, with an entrance placed on the apse side and the altar on the old face where the signs of an upper opening (rose or arched window) are still visible; the date 1622 is inscribed above the entablature of the current entrance. The original bell tower, which was leaning, was demolished at the end of the 18 th century and substituted with the current one. The convent, on the other hand, has undergone various transformations and adaptations, maintaining only a few hints of the original construction, among which are some of the arches in the cloister. The complex is currently used as a museum, which includes an auditorium for shows and meetings. The Archaeological Museum is dedicated in part to the history and archaeology of the Aso River Valley and in part to the archaeological discoveries made over the course of the 19th and 20th centuries. The museum also houses a library, which contains around 45,000 volumes, and the "Giano" Centre for Environmental Education, instituted by the Marche Region in 2001.

\subsection{Architectural Complex Description}

Beginning in 1247, when the Complex was founded, until the most recent restorations following the earthquake that hit the area in 1997 were finished in 2007, the entire San Francesco complex has not only changed in its use (a minor prison starting in 1861, a grain storehouse during the Fascist period, a woodworking shop, and recently taken over by the city for cultural activities), but has also undergone a series of substantial formal modifications that have defined its current structure consisting of different architectural elements, all of which are juxtaposed and connected to form a single, complex architecture.

The following external characteristics are found in the San Francesco complex:

- it is located on a promontory (the highest point of the historical centre) and is accessible either from the façade of the church, which is located at the top of a system of stairs that draws attention to a considerable change in elevation with respect to the road in front (Figure 1), or from the right side (commonly used access), which can be reached via a very steep road;

- the free access space around the Complex cannot be assigned to a single plane, but rather presents an elevation profile with notable height differences and in some particular points (the bell tower), also a very reduced width;

- the walls are mainly in bare brick save one part of the southern wall of the church which shows a mixture of brick and square stone (probably Istrian stone);

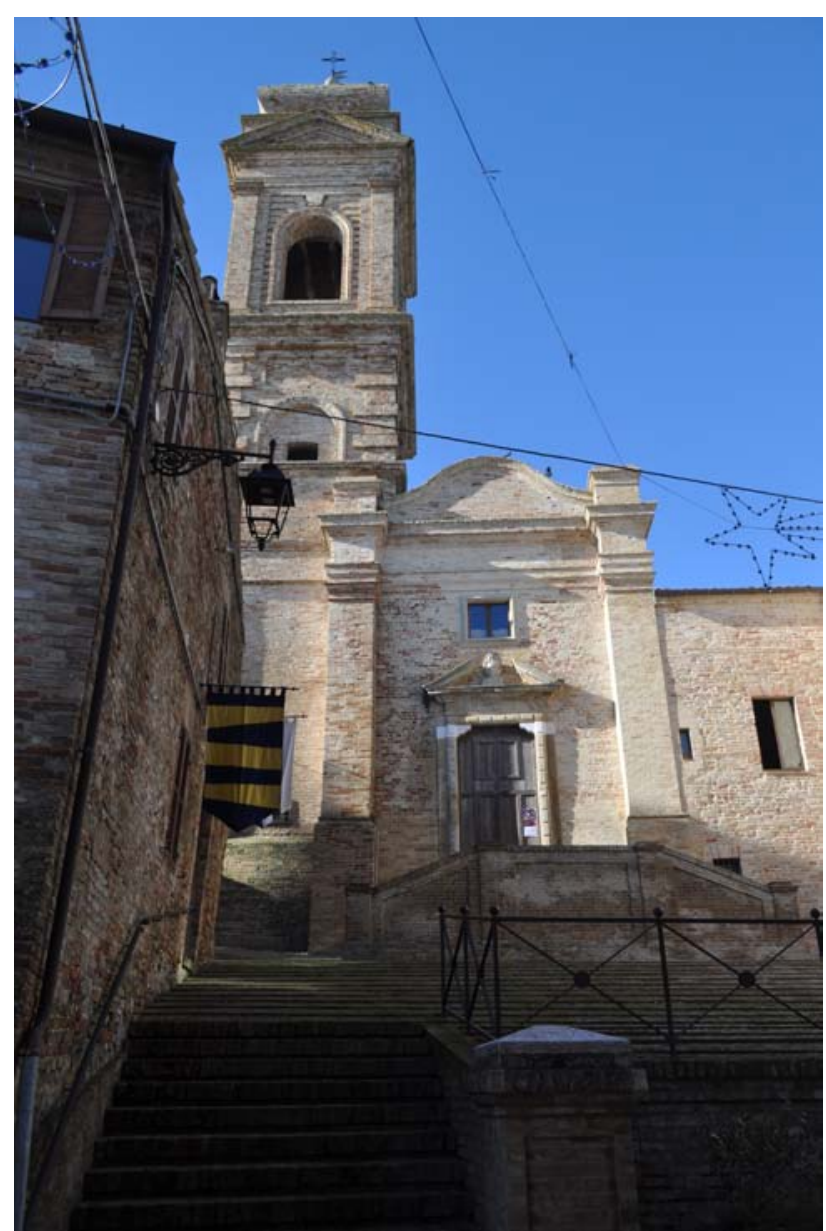

Figure 1. Front of the church with the monumental staircase

- the surrounding construction follows the orography, which means the structures meet the ground at very different elevations; some are even much lower than the level of the San Francesco complex.

Internally, the church and convent present the following aspects from the organisational and distributional points of view:

- the church, choir, and bell-tower base form a single body, the main body of the monastic Complex;

- the church, which is the main element, consists of a single nave covered by Gothic groin vaults resting on bare brick columns; there are diverse decorative elements on the side walls such as altars, traces of frescoes, and plaster;

- the choir, covered by a groin vault with raised ribs, is situated at a higher level on the counter-façade (the part inside the entrance), therefore exhibiting a double level facing the nave of the church;

- the tall, soaring bell tower is located to the left of the church entrance. At the nave level of the church, the base of the tower is composed of a small environment located slightly off the ground and covered by a barrel vault in bare brick, while the floor is in clay. At the level of the choir, a C-shaped scale can be accessed, which, in a reduced space, allows a higher elevation of the bell tower to be reached;

- what remains of the adjacent cloister is composed of a sequence of groin vaults on two sides, of which only one is still an open portico. The court is currently marred by a tank for drinking water;

- $\quad$ on the left-hand side of the church (north side) there are many rooms all linked together but placed at different levels, thus generating a complex spatial organization. The roofing 
systems of such rooms are varied: sexpartite vaults, cloister vaults, buttresses, and lunettes, along with flat ceilings and wooden trusses;

- finally, another interesting element is the underground cavities, galleries, and tunnels. The presence of environments carved out of the ground is a characteristic found in many historical town centres in the Marche Region. They are spaces that have been used over the centuries for different purposes such as water cisterns and wells, areas for living and conserving food, defensive areas, religious and burial spaces, pits to extract materials for construction, and factories to process agricultural products.

\section{DATA-CAPTURE METHODOLOGY}

This part of the article illustrates the main phases of the project workflow, in which the design and experimentation of an appropriate "survey project" obviously form the first crucial step. This phase serves to consider the objectives, critical aspects, and choices adopted considering the instruments used. Such a description is also directed at identifying a methodology that can be used in other similar cases.

Given the area in which the survey described here was carried out and the skills involved (architects, structural engineers, historians, and restoration experts), the general objective was to provide careful documentation and a representation of the current state of the San Francesco Complex to be used for multiple aims, such as: i) an overall reading of the entire building and its arrangement; ii) understanding and analysis of the structural system derived from the superposition of historical modifications that, in the context of the project, can help to interpret its behaviour over time; iii) analysis aimed at monitoring and managing the site; and iv) research to verify the historical phases by integrating and comparing the survey to archival sources in order to identify the traces and stratifications that have occurred over time.

\subsection{Planning the integrated survey}

Considering that surveying is an activity aimed at collecting geometrical, spatial, and material information, it is necessary to provide for and establish the maximum level of detail desired from the subsequent representations. Coordinated work between the skills involved therefore identified an accuracy (metric precision) of data capture in order to then obtain further modelling at more detailed levels in a scale interval from 1:50 to $1: 20$ according to the dimension/object of the depiction.

After this, an in-depth survey was made to make preliminary observations of the dimension and overall shape of the architectural structure and the morphological characteristics of the site, as well as the meteorological/environmental conditions and/or the presence of elements of physical obstruction around the building. This essentially dealt with a careful and, where possible, exhaustive evaluation of the different factors that can influence, sometimes profoundly, the quality of the data acquired in order to define: i) methodologies and instruments that are more adapted to surveying; and ii) correct planning of the data-capture phase in terms of both the quality of information and the time and resources used.
Once the objectives were clarified, the level of detail of the models identified, the possible critical on-site aspects considered along with the overall characteristics of the building and the site described in the preceding section, a point-cloudbased surveying campaign was undertaken using an approach capable of integrating terrestrial range-based data acquired using TOF laser scanners with aerial photogrammetry using a UAV equipped with a remote-oriented camera.

The methodology for data capture was also selected based on the case study, that is, on the particular position related to the geomorphological structure of the site so that each of the chosen technologies could provide information where another presented "gaps". Essentially, while the laser scanner could control possible areas hidden from below, the use of photography using the UAV allowed zones hidden from above to be controlled and also to photograph considerably high parts (roofing and the bell tower).

The same high-resolution photographs would be used to texturise the entire 3D model, in order to increase the level of representative realism and to improve the quality of detail where 3D data would not be capable of describing the exact geometry.

As is obvious, because a database composed of point clouds was elaborated, it was also important to be able to use SFM tools to generate point clouds from the photographs. For this reason, an approach capable of integrating data from the laser scanner and images captured with the UAV represented the best solution for our goals. The combination of such instruments, which produce homogeneous data (point clouds), allowed them to be fused together, creating a redundancy of $3 \mathrm{D}$ information, which could then provide information for different uses with different levels of detail. (Figure 2)

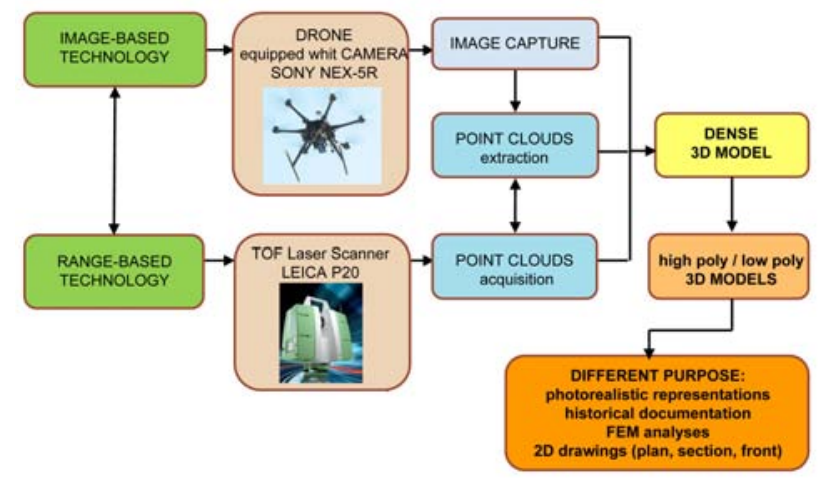

Figure 2. Survey flow-chart

The survey campaign, conducted in February 2014, was undertaken in two phases separated by about two weeks. Such a time lapse prevented us from using a target network placed on the ground and along the building perimeter, which would have simplified and improved the accuracy in recording the point clouds obtained from different types of data-capture instruments.

The first surveying session dedicated to photography using the UAV took place in one morning; the second, dedicated to $3 \mathrm{D}$ laser scanner data acquisition, took place over four days full of field work. 


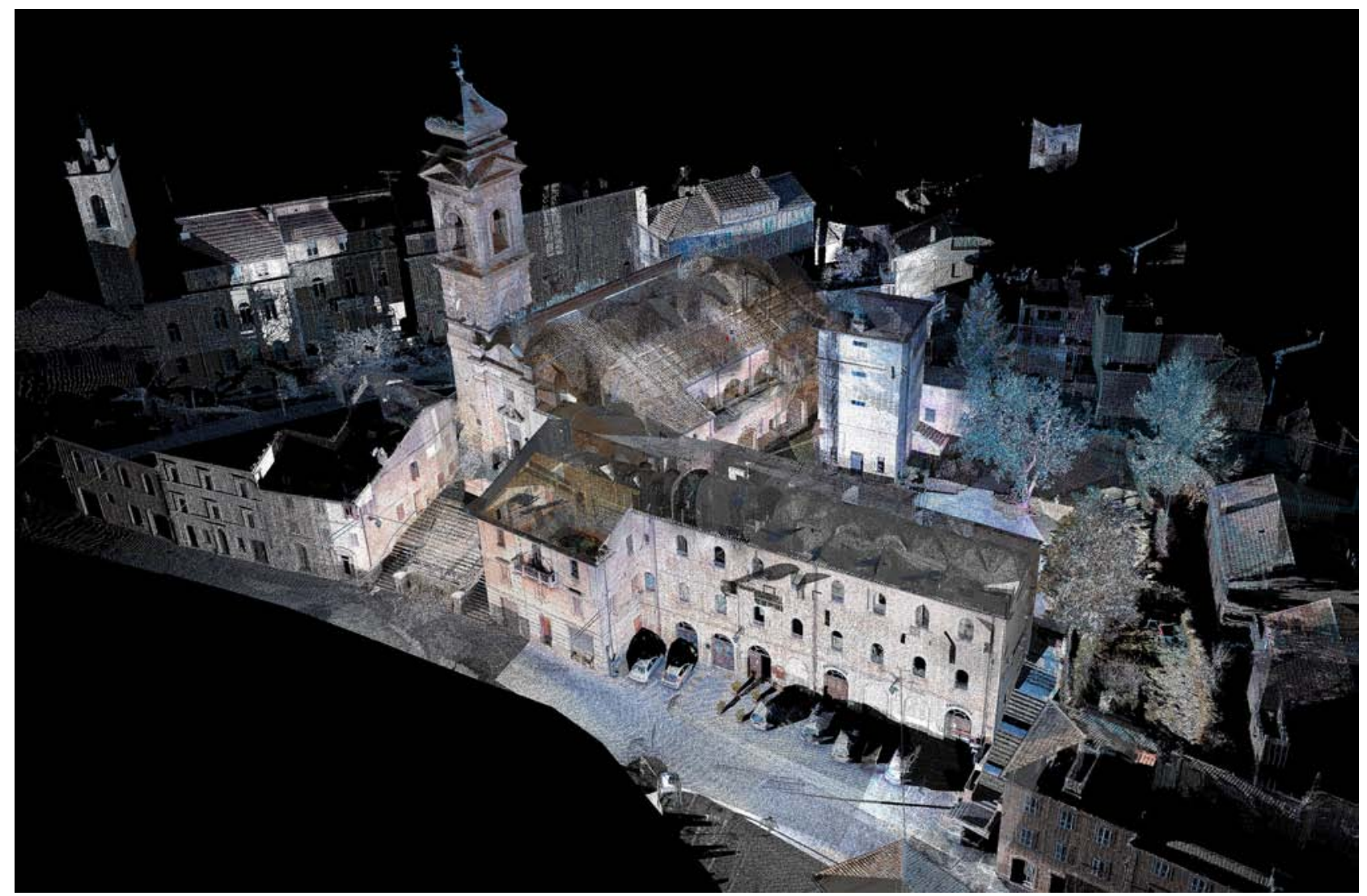

Figure 3. Merged point cloud from TOF scanner

\subsection{D Laser Scanning}

The range-based survey was made using a Leica P20 TOF laser scanner. Laser scanner technology was used for 3D geometrical data acquisition both inside and outside the San Francesco Complex. Given the principal characteristics of the specific instrument and the architectural construction, the survey was designed to use a multi-resolution approach. Different scanning layouts (sampling densities) were used in relation to the level of detail and geometrical complexity of the parts surveyed and as a function of the working distances from the surfaces to be scanned. In particular, for the inside, with scanning station positions less than $10 \mathrm{~m}$ from the part of the wall to be surveyed, a resolution of $12.5 \mathrm{~mm}$ at $10 \mathrm{~m}$ was fixed. Different resolutions were used for the exterior:

- $6.3 \mathrm{~mm}$ at $10 \mathrm{~m}$ (for data acquisition at distances between 10 and $20 \mathrm{~m}$ from the external surfaces with a scanning time of $1 \min 49 \mathrm{~s})$;

- $12.5 \mathrm{~mm}$ at $10 \mathrm{~m}$ (in cases where the surrounding site conditions constrained working distances to less than $10 \mathrm{~m}$ from the surface);

- $3.2 \mathrm{~mm}$ at $10 \mathrm{~m}$ (for scans that involved the high bell tower).

For such a set of resolutions, the times used for the individual scans ranged from a minimum of $58 \mathrm{~s}$ to a maximum of $3.5 \mathrm{~min}$. Each scan was made covering an area of $360^{\circ} \times 270^{\circ}$. In defining the external scan position, the possibility of acquiring part of the morphological site was considered along with the elevation profile of the streets in the immediate vicinity of the object of study.

The 3D digitising campaign was completed with a total of 83 scans, of which 26 were external and 57 were related to internal environments (Figure 3).

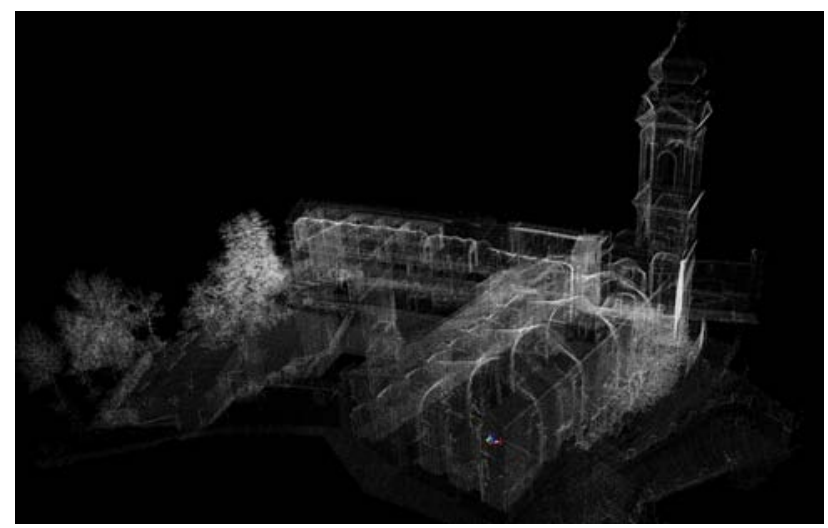

Figure 4. The ogival vault system inside the church

The possibility of designing the survey to acquire wide common surface areas (between the different internal environments, the external walls, and the interior and exterior with scans positioned on the openings) allowed us to use the cloud-tocloud recording method, permitting the scans to be connected together (Figure 4). For the exterior, the distances between the scanning stations were different based on the conditions of the context, but anyway guaranteed the superposition of partial point clouds.

The entire data set acquired was 421 million points. To manage and share this enormous amount of data with the other subjects involved (engineers, restorers, etc.), a platform equipped with the TruView visualisation plug-in was set up to share the 3D data both on-line and off-line. The platform included all the point clouds acquired with the aim of effortlessly exploring both the entirety of all the aligned point clouds datasets recorded with indications of all the scan positions and all the different scans made. 


\subsection{UAV Data Capture}

Regarding the image-based survey, photography via UAV was necessary to capture not only the textures, but especially building geometries not reachable with the laser scanner, such as the roof and the bell tower, which is richly decorated with mouldings that were inevitably under shadow in the laser scanner data. This method allowed us to experiment and test data-capture techniques with the UAV for photogrammetry applications. In Italy, low-altitude flights with such aerial vehicles is not currently regulated with precise legislation, but there are some under study that will shortly limit their use based on different aims of the flights (recreation- or job-based).

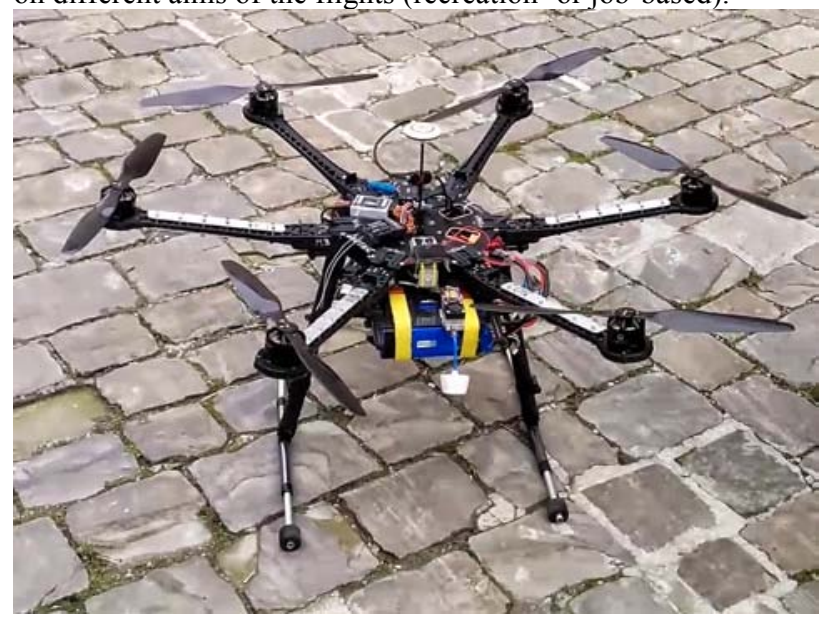

Figure 5. UAV used for surveying

In planning the surveying operations, the choice of this instrument required some preliminary evaluation pertaining to the site conditions, both from the elevation and geomorphological points of view and regarding the meteorological aspects (the direction and speed of the wind) and lighting conditions.

While not at an excessive altitude (463 $\mathrm{m}$ above sea level), the location of the San Francesco convent within the historical centre of Monterubbiano is at the highest point and completely open towards the Aso Valley, so it is very exposed to wind. As for the lighting conditions, the important factor is the need to avoid sharp shadows and marked radiometric differences within the sequence of images to be taken. For this reason, the weather forecast was studied ad hoc to find a day with low wind speed that possibly overcast but where the cloud cover was high enough that it would not rain.

The aerial vehicle used had 615 "-diameter rotors and was powered by $6-400 \mathrm{kV}$ brushless electric motors, with 2-22 V 5A LiPo batteries connected in parallel. The control unit was composed of 3 gyroscopes, 3 accelerometers, a magnetometer, a barometer, and a GPS. It was $80 \mathrm{~cm}$ in diameter and $40 \mathrm{~cm}$ high, with a total weight (without camera) of $7 \mathrm{~kg}$ and a maximum carrying capacity of $2.5 \mathrm{~kg}$. The duration of each flight with charged batteries was $8 \mathrm{~min}$, and the speed ranged from 0 to $10 \mathrm{~m} / \mathrm{s}$ (Figure 5) (Figure 6) .

These characteristics were kept in mind while planning the survey since they determine the distinctive aerodynamic capabilities and control of the flight paths of these aerial vehicles. It was also considered how the current configuration ignored the existing physical obstacles that could be encountered during flight, so the flight paths were carefully studied during planning to keep the drone always in view and also to identify areas to facilitate take-offs and landings.

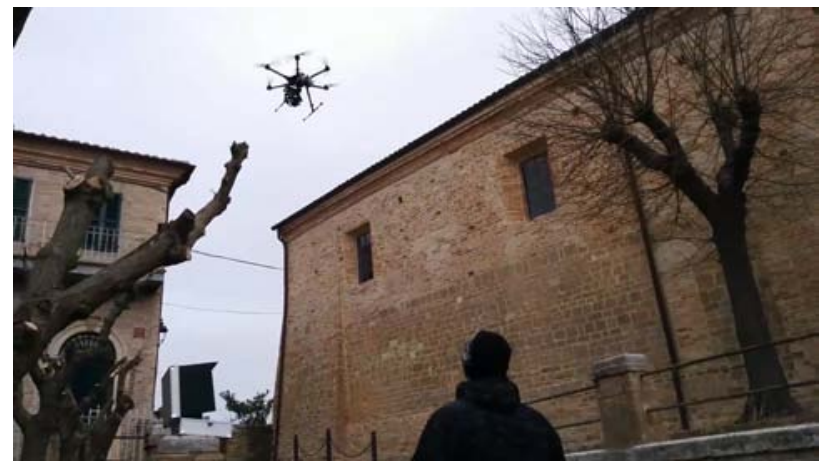

Figure 6. The UAV flying around the convent

The entire photography campaign was made using a Sony NEX5R camera with a fixed focal length of $22 \mathrm{~mm}$ and an APS-C sensor $(23.4 \times 15.6 \mathrm{~mm})$ with a maximum resolution of $4912 \mathrm{x}$ 3264 (16,032,768 pixels), yielding a physical pixel dimension of $0.004763 \mathrm{~mm}(\mathrm{p}=23.4 \mathrm{~mm} / 4912)$.

The camera had been previously calibrated with the use of a grid of 4 coded targets provided by the Photomodeler software. Knowing the camera characteristics used in relation to the characteristics of the object to be photographed is fundamental in planning the survey campaign. The focal length, for example, influences the ideal number of images to take and thus the resolution of the final point cloud. In order to assess the means of image-taking in advance, that is, the distribution of images required to cover the entire surface of the building and the shaded zones as much as possible, the main rules of shooting required by the software used in the subsequent elaboration (orientation) of the images (minimum overlay, convergence, etc.) were considered.

Therefore, considering all of these details, four flights were made after identifying additional take-off/landing areas, one for each approachable face of the architectural Complex. Considering the time needed for take-off and landing, moving in the take-off areas identified, substituting the batteries, as well as the length of each flight, the entire photographic survey campaign lasted about an hour and a half.

Each flight was made manually (without set automation) and at a low, variable speed. The flight paths were primarily linear (horizontal and vertical motion) except around the bell tower, where the motion approximated circular motion in several different horizontal planes. Consequently, even the height of the flights was necessarily varied.

A total of 517 images were taken with a point of view that varied as a function of the building conditions surrounding the architectural Complex. The position of the camera on the aircraft was set to be able to take images that were inclined with respect to the building's vertical surface (to view the shaded areas from above). The shooting frequency was one every two seconds, while the speed of the drone, although low, was not exactly constant, so the superposition between adjacent photos wound up ranging from 60 to $80 \%$, which was, however, enough to extract coherent 3D information. 


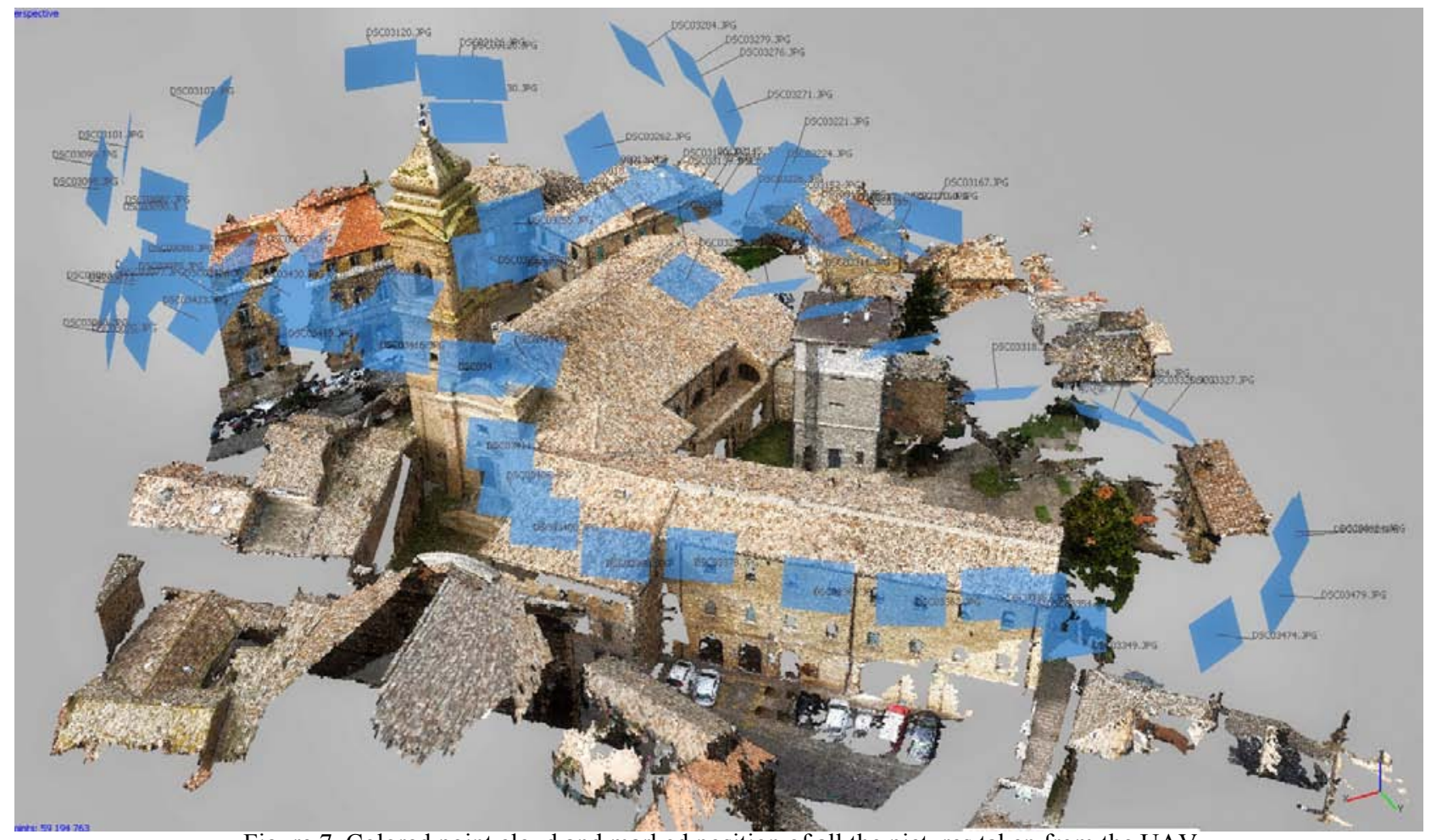

Figure 7. Colored point cloud and marked position of all the pictures taken from the UAV

\section{DATA PROCESSING}

The UAV campaign produced 517 photographs in RAW and JPG format. From a first look at the lighting conditions of all of the photographs, we chose to use the JPG images directly without corrections via RAW processing. We then proceeded to qualitatively analyse the photographs, discarding about 310 because they were blurry. Of the remaining images, 129 were selected based on the quality and coverage of the subject. The 129 images, in which radial distortions were eliminated using Photomodeler, were processed with Photoscan in order to obtain a dense points cloud.

The next step was to orient the photographs. Analysing the sparse point cloud obtained through orientation, some notable zones presented points that moved away from the model significantly in the processing phase. Using to such points, it was possible to identify further problematic (blurry) images. Such images were eliminated from the processing, reducing the total to 93 photographs.

Once the 93 photos were oriented and no alignment errors were found, extraction of the dense point cloud was started with the "high" setting. Once the point cloud was obtained and cleaned of all outliers and points not pertaining to the subject of interest, a total of 39 million points $(38,959,834)$ remained (Figure 7). Parallel to this, processing of the point cloud obtained from the laser scanner campaign was undertaken. The external stations (26) were united and decimated, retaining one point every centimetre. In order to align the point clouds from the two campaigns, it was necessary to scale the point cloud produced by processing images taken by the drone.

We then proceeded to identify a reference length for both point clouds (Figure 8).
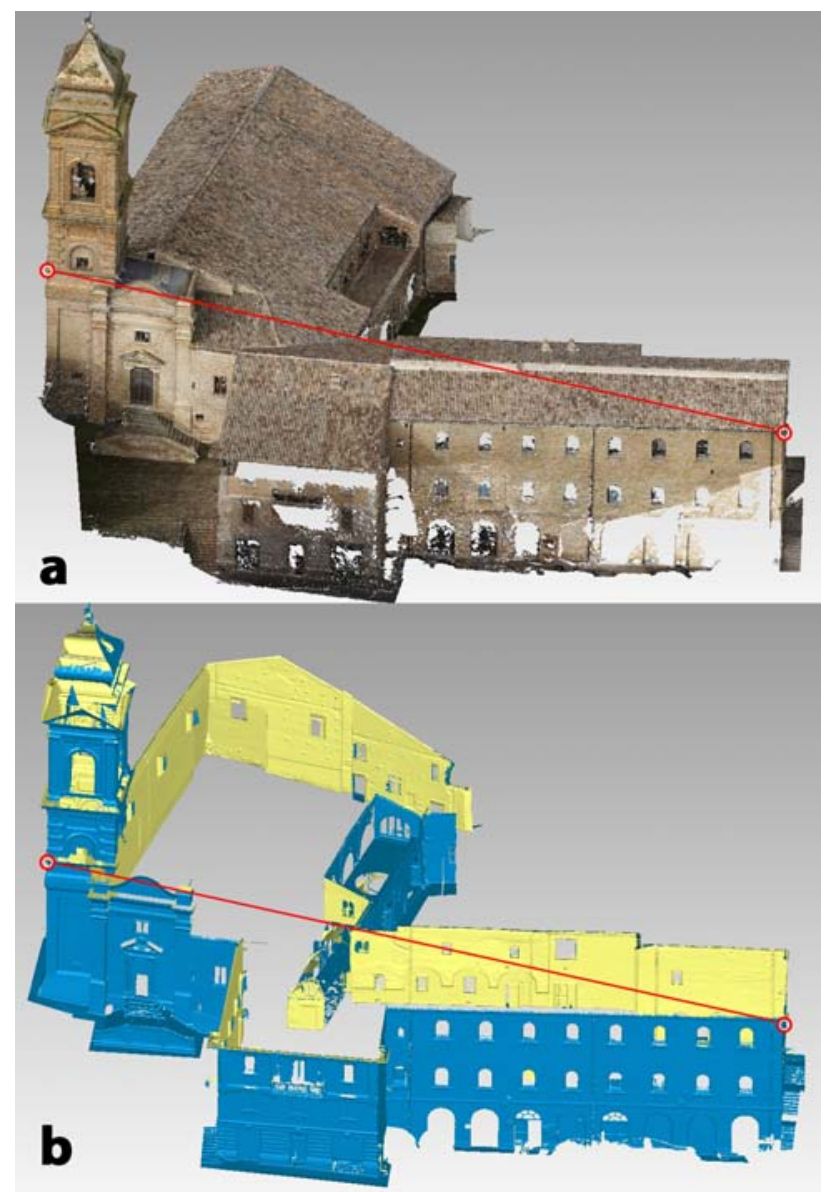

Figure 8. The red line used as a references lenght to align the point clouds captured from UAV (a) and TLS (b) 


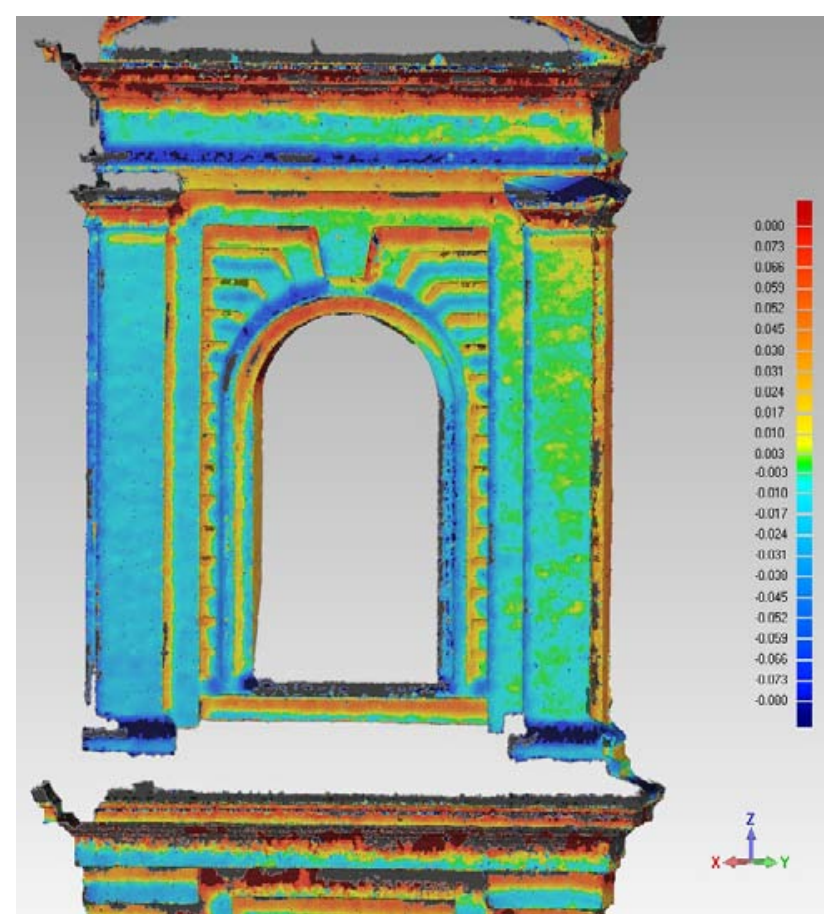

Figure 9. Deviation analysis of a detail of the complex

The extreme points of the straight line were identified near corners of the building (unaligned, distant enough, and visible to both systems).

Alignment was made using Geomagic Studio software. Such a program allows for a best-fit alignment only between one mesh and one point cloud. Since it was not possible to align two point clouds automatically, the point cloud coming from the scanner was tessellated using the proprietary meshing Wrap algorithm in Geomagic, which is better adapted to reconstructing architectural constructions than other meshing algorithms (Poisson, for example), which would have generated a model with corners that were too soft and smoothed.

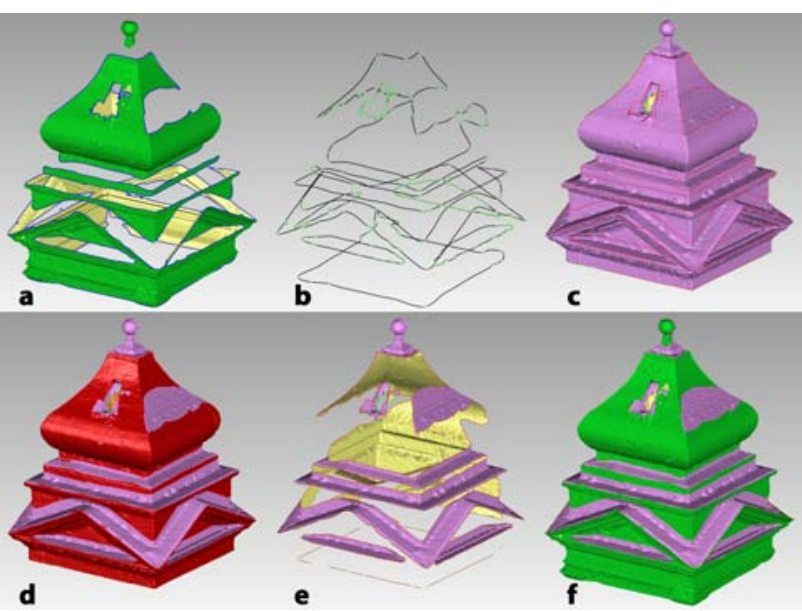

Figure 10. (a) Scanner data and hole boundaries highlighted; (b) hole boundaries extracted; (c) hole boundaries projected on UAV data; (d) selection of overlapping areas on UAV data using projected boundaries; (e) UAV data fitting scanner data holes; (f) scanner data merged with UAV data.

Once alignment using the best fit was made, an additional adjustment was made to decrease the deviation between the two point clouds. The average resulting deviation was $3.9 \mathrm{~cm}$.

To better establish and verify the accuracy of the alignment, different parts of the model were analysed using complete data from the two point clouds without applying any decimation (Figure 9).

Once the models were aligned, the merging phase was started. The laser scanner data were left unchanged while all the superimposed parts of the drone point cloud were eliminated, leaving only the parts necessary to fill in the scanner point cloud gaps. Such a procedure allowed a complete model of the coverage to be obtained, which was almost completely absent in the laser scanner data.

Division of the drone point cloud into parts in order to merge it with the scanner model and parts to be eliminated was done by

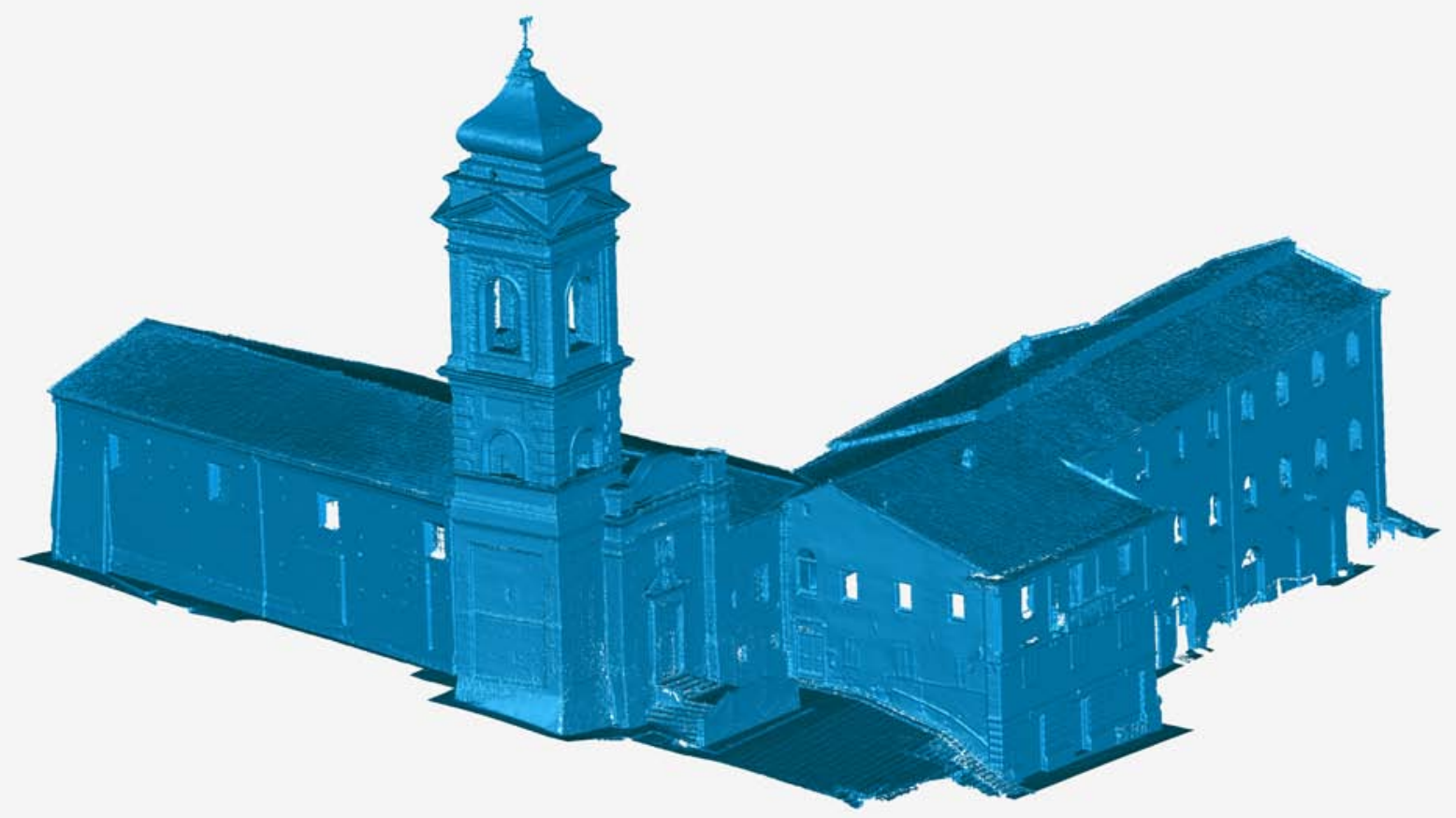

Figure 11. 3D model obtained using wrap method in Geomagic 
identifying the gap edges on the mesh derived from the laser scanner. The contours were converted into curves, which were then transferred to the mesh derived from the drone data.

This allowed us to use the curves as a boundary to eliminate the extra parts, i.e., those overlaying the scanner data.

Such a procedure allowed a complete model of the roof to be obtained, which was almost entirely absent from the laser scanner data (Figure 10).

The 3D model obtained, which was free of textures, was used by the team of engineers dedicated to structural verifications to analyse the layout of the building, identify the main volumes, and plan the ideal level of detail to undertake structural analysis.

\subsection{Future Work}

Based on such analysis and observations, a later phase of the research will concentrate on a simplified 3D model composed of surfaces that describe the building in its main areas, but which is useful for processing in an FEM analysis.

The 3D model will be texturized by projecting on it the highresolution photo obtained by the photographic equipment mounted on the drone.

This phase will have different approaches and workflows according to the level of detail desired:

- to texturize the complete 3D model for use in overall views (3D pdf, 3D on-line player, etc.), a mesh will be used with a low number of polygons on which the aerial photos will be projected and blended using orientations of the photographs obtained using SFM technique;

- to generate orthographic images, which will be useful to restorer or historian for wall-material analysis or for the definition of crack patterns, portions of a non-decimated 3D model will be used, onto which both the aerial and terrestrial photographs will be projected (Figure 11).

In this case, the projection of the photographs will be made using specific 3D-studio-type software tools (Autodesk 3ds Max). In such a software environment, the photographs oriented using SFM technique will be projected making use of ad hoc scripts aimed at automating procedures to import the viewpoints, material generation for photograph projection, and rendering. Regarding the land-based photographs, for we have no information on the position and orientation with respect to the $3 \mathrm{D}$ model, these will be positioned given some reference measurements on the three spatial axes both on the 3D model and the photographs through utilities such as "camera match" in $3 \mathrm{ds}$ Max, which, recognising homologous points, allows the $3 \mathrm{D}$ model and photographs to be aligned.

\section{CONCLUSION}

The goal of this research was to test a workflow to define a methodology for surveying, processing and representing the Convent of San Francesco in Monterubbiano (Marche, Italy), useful also for similar architectural complex.

The survey was based on the integration of $3 \mathrm{D}$ data coming from a terrestrial TOF laser scanner and photographs taken by UAV. These images permitted us to record parts of the building can not be reached by terrestrial laser scanners. The aerial images were then processed with SFM techniques in order to obtain a points cloud. In a further phase this points cloud was aligned and merged with the points cloud captured by the TOF laser scanner.

This cloud to cloud process data has allowed the construction of a dense $3 \mathrm{D}$ model from which to derive, in a future phase of the

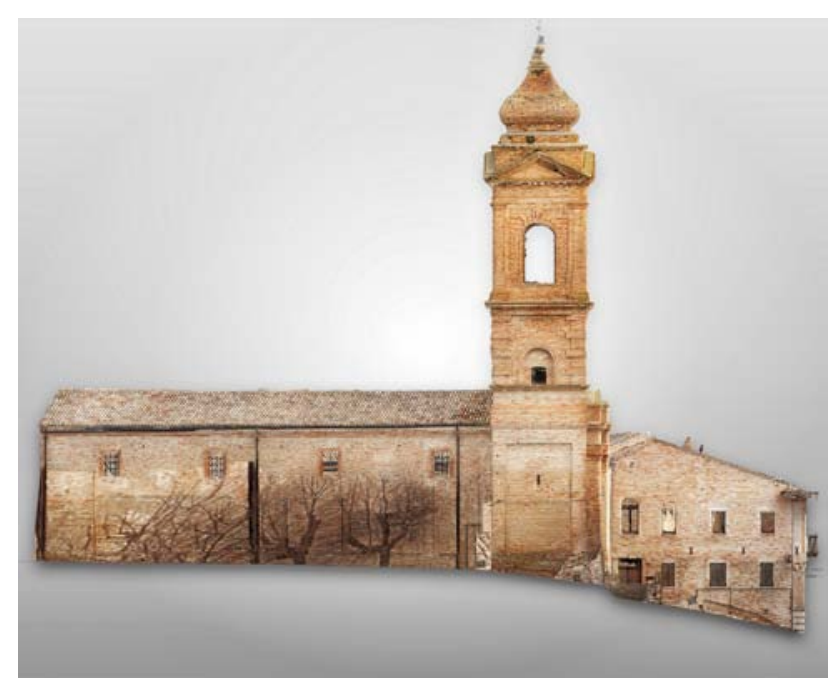

Figure 11. Orthogonal projection of 3D model with rough textures

research, models textured with aerial images, with different levels of detail useful for different analysis by the members of the team of scholars involved in the experimentation (architects, structural engineers, restorers, historians). Such analysis will allow us to evaluate all the phases of our approach (data capture and data processing) in relation to the quality of the results obtained.

\section{REFERENCES}

Beraldin A., 2004, Integration of laser scanning and closerange photogrammetry - The last decade and beyond. International Society for Photogrammetry and Remote Sensing (ISPRS) Congress, Commission VII, Istanbul, Turkey. 2004 pp. 972-983.

Colomina I. and Molina P., 2013. Unmanned aerial systems for photogrammetry and remote sensing: A review. ISPRS Journal of Photogrammetry and Remote Sensing 92 pp 79-97

El-Hakim, S. F., Beraldin, J. A., Picard, M., and Godin G., 2004, Detailed $3 D$ reconstruction of large-scale heritage sites with integrated Techniques, IEEE Computer Graphics and Application, 24(3), 2004, pp. 21-29.

Fiorillo, F., Jiménez, B., Remondino, F., Barba, S., 2012. 3D surveying and modeling of the archaeological area of Paestum, Italy. Virtual Archaeol. Rev. 4, 55-60.

Guidi, G., Russo, M., and Beraldin J-A., Acquisizione $e$ modellazione poligonale, Ed. McGraw Hill, 2010.

Micoli, L., Guidi, G., Angheleddu, D., Russo, M., 2013 A multidisciplinary approach to $3 D$ survey and reconstruction of historical buildings, Digital Heritage International Congress (DigitalHeritage) proceedings, 2013, Volume: 2, pp. 241 - 248

Remondino, F., 2011. Heritage recording and $3 D$ modeling with photogrammetry and $3 D$ scanning. Remote Sens. 3, pp. 1104-1138.

Saleri, R., Cappellini V., Nony, N., De Luca, PierrotDeseillingy, M., Bardiere, E., Campi, M., 2013, UAV Photogrammetry for archaeological survey: The Theaters area of Pompeii Digital Heritage International Congress (DigitalHeritage) proceedings, 2013, Volume: 2, pp. 497 - 502 